\title{
Evolution and Comparative Genomics of Odorant- and Pheromone-Associated Genes in Rodents
}

\author{
Richard D. Emes, ${ }^{1}$ Scott A. Beatson, ${ }^{1,2}$ Chris P. Ponting, ${ }^{3}$ and Leo Goodstadt \\ MRC Functional Genetics Unit, Department of Human Anatomy and Genetics, University of Oxford, Oxford OX1 3QX, UK
}

\begin{abstract}
Chemical cues influence a range of behavioral responses in rodents. The involvement of protein odorants and odorant receptors in mediating reproductive behavior, foraging, and predator avoidance suggests that their genes may have been subject to adaptive evolution. We have estimated the consequences of selection on rodent pheromones, their receptors, and olfactory receptors. These families were chosen on the basis of multiple gene duplications since the common ancestor of rat and mouse. For each family, codons were identified that are likely to have been subject to adaptive evolution. The majority of such sites are situated on the solvent-accessible surfaces of putative pheromones and the lumenal portions of their likely receptors. We predict that these contribute to physicochemical and functional diversity within pheromone-receptor interaction sites.
\end{abstract}

[Supplemental material is available online at www.genome.org.]

Genome sequences are providing an opportunity to investigate evolutionary phenomena that are absent from the paleontological record. Whereas adaptation is consistently invoked in accounting for morphological changes that are apparent in extant and fossilized organisms (Hughes 1999), its contribution to the distinctive behavioral responses of animals is less understood. The diversifying effects of adaptive evolution on genes can be revealed from comparisons of their sequences. Analysis of virtually complete sets of genes from the two rodents Rattus norvegicus and Mus musculus (Waterston et al. 2002; Rat Genome Sequencing Project Consortium 2004), which diverged 12-24 million years ago (Mya; Adkins et al. 2001), now allows observations of the impact of diversifying selection on each of their genes during this relatively short time period.

Prominent among genes that have been associated with rodent behavior are the pheromone receptors expressed in the vomeronasal organ (VNO; Dulac and Torello 2003). This is an olfactory organ for the detection of chemical cues, situated in the septum of the nose. Deletion of a cluster of mouse vomeronasal type-1 receptor-like (V1R-like) genes (Dulac and Axel 1995; Ryba and Tirindelli 1997) results in significant modification of male and female behavioral responses, including reduced male libido and inappropriate maternal aggressive behavior (Del Punta et al. 2002). V1Rs are seven-transmembrane (7TM) proteins and are members of the G-protein coupled receptor (GPCR) superfamily.

V1Rs are closely related to a second family of GPCRs, the olfactory receptors (ORs), that are expressed in the olfactory epithelium. This is one of the largest gene families identified. The mouse genome has $\sim 1500$ OR genes, and the human $\sim 900$ (Young and Trask 2002). The dynamic nature of the evolution of this family is characterized by rapid expansion, gene duplication, extensive gene loss by pseudogene creation, and diversifying selection (Lane et al. 2001; Waterston et al. 2002; Young et al. 2002). In mouse, $20 \%$ of ORs are pseudogenes, whereas this fraction is much higher $(\sim 60 \%-70 \%)$ in humans (Rouquier et al.

\footnotetext{
These authors contributed equally to this work.

2Present address: Division of Immunity \& Infection, University of Birmingham. Birmingham, B15 2TT, UK.

${ }^{3}$ Corresponding author.

E-MAIL Chris.Ponting@anat.ox.ac.uk; FAX 44 (0)1865 272420.

Article and publication are at http://www.genome.org/cgi/doi/10.1101/ gr.1940604.
}

1998; Glusman et al. 2001; Zhang and Firestein 2002). The reduction in the human OR gene repertoire is postulated to be reflected in a poorer sense of smell (Young et al. 2002). A family of OR-like molecules have been found to be expressed in the testes of humans and dogs (Vanderhaeghen et al. 1997), and members have been localized to the spermatozoa where they have been linked to chemotaxis (Spehr et al. 2003).

V2Rs are members of family C GPCRs and are also expressed in the VNO (Matsunami and Buck 1997; Ryba and Tirindelli 1997). These receptors are similar to metabotropic glutamate and calcium-sensing receptors in possessing an $\mathrm{N}$-terminal extracellular region and a C-terminal 7TM GPCR region (Matsunami and Buck 1997; Ryba and Tirindelli 1997). Based on studies of a goldfish V2R-like molecule which binds arginine and lysine (Speca et al. 1999), it appears possible that V2Rs bind protein rather than volatile organic compounds. This is consistent with observations that the V2R extracellular regions are homologous to bacterial proteins with amino acid-binding properties (Kunishima et al. 2000; Hermans and Challiss 2001).

In common with other GPCR superfamily members, ORs, V1Rs, and V2Rs present considerable challenges in the elucidation of their structures, functions, and evolution. GPCRs are characterized by an extracellular N-terminus, a cytosolic Cterminus, three cytosolic loops, and three extracellular loops (Filipek et al. 2003). The GPCR fold is represented by crystal structures of a single eukaryotic protein, bovine rhodopsin (Okada et al. 2002; Filipek et al. 2003), to which many GPCR family members such as V1Rs and V2Rs cannot be modeled with accuracy. In general terms, however, structure-function relationships for GPCRs are well established: extracellular ligands bind within the 7TM region and induce conformational changes that are coupled to the binding of intracellular G-protein heterotrimers (Wess 1997; Filipek et al. 2003). Nevertheless, the understanding of structure-function relationships for specific GPCRs is far from complete. This has lead to many sequence- and structure modeling-based studies dependent on the assumption that amino acids within functional sites are particularly well conserved (Floriano et al. 2000; Singer 2000; Oliveira et al. 2002; Vaidehi et al. 2002; Cavasotto et al. 2003).

Several pheromonal cues are known to directly affect rodent behavior. Aphrodisin, a female hamster lipocalin homolog present in the vaginal discharge, induces copulatory behavior in the 
Table 1. Summary Information of Families Analyzed

\begin{tabular}{lccr}
\hline Family & $\begin{array}{c}\text { Number of } \\
\text { genes } \\
\text { analyzed }\end{array}$ & $\begin{array}{c}\text { Median } \\
\text { per gene } \\
\mathbf{K}_{\mathbf{A}} / \mathbf{K}_{\mathbf{s}}\end{array}$ & $\begin{array}{c}\text { Number } \\
\text { of } \boldsymbol{\omega}^{+} \\
\text {sites }\end{array}$ \\
\hline OR Family A & 10 & 0.362 & 2 \\
OR Family B & 10 & 0.414 & 9 \\
OR Family C & 10 & 0.199 & 2 \\
OR Family D & 13 & 0.311 & 14 \\
OR Family E & 16 & 0.319 & 22 \\
Human Testis-specific & 31 & 0.276 & 4 \\
OR orthologs: Rat & & & \\
Human Testis-specific & 20 & 0.271 & 1 \\
$\quad$ OR orthologs: Mouse & 22 & 0.614 & 14 \\
V1R & 9 & 0.321 & 12 \\
V2R & 35 & 0.629 & 32 \\
MUP/ $\alpha_{24}-$ globulin & 12 & 0.533 & 33 \\
OBP & 38 & 0.479 & 25 \\
LUP & 12 & 0.619 & 50 \\
MHC-M10 & 12 & 0.028 & $\mathrm{n} / \mathrm{d}$ \\
G protein- $\alpha$ & 8 & 0.025 & $\mathrm{n} / \mathrm{d}$ \\
G protein- $\beta$ & 10 & 0.081 & $\mathrm{n} / \mathrm{d}$ \\
G protein- $\gamma$ & & & \\
\hline
\end{tabular}

Median $\mathrm{K}_{\mathrm{A}} / \mathrm{K}_{\mathrm{S}}$ values were calculated from pairwise comparisons using yn00 (Yang and Nielsen 2000). The number of $\omega^{+}$sites (nonconserved alignment positions predicted to be under positive selection with a posterior probability $P>0.90$ by one codeml model and $P>$ 0.50 by at least one other model) predicted by codeml using the PAML package (Yang 1997; Yang and Nielsen 2002).

male (Singer et al. 1986; Briand et al. 2000). Urinary and other scent compounds influence rodent mate selection, estrus synchronization (Whitten effect; Whitten 1958; Novotny et al. 1999), estrus suppression (Lee-Boot effect; Lee and van der Boot 1955; Ma et al. 1998), male-induced termination of pregnancy (Bruce effect; Bruce 1968), and puberty acceleration (Vandenbergh effect; Vandenbergh 1976, 1989).

Mouse major urinary proteins (MUPs) and their counterparts in rat, termed $\alpha_{2 u}$-globulins, have also been shown to influence puberty acceleration. These genes show a high degree of sequence polymorphism, including differences between laboratory mouse strains (Robertson et al. 1996). MUPs and $\alpha_{2 u^{-}}$ globulins are lipocalins whose tertiary structure consists of an eight-stranded antiparallel $\beta$-barrel enclosing an internal ligand binding site (Flower 1996; Cavaggioni and Mucignat-Caretta 2000). MUPs and $\alpha_{2 u}$-globulin genes are largely expressed in the liver, under stimulation by androgens, and become concentrated in the urine by filtration from the blood serum (Knopf et al. 1983; Mucignat-Caretta et al. 1995; Flower 1996; Novotny et al. 1999; Cavaggioni and Mucignat-Caretta 2000). They are thought to stimulate behavioral responses either directly at close proximity (Mucignat-Caretta et al. 1995; Hurst et al. 2001) or by air-borne delivery of volatile compounds (Novotny et al. 1999).

Odorant binding proteins (OBPs) are additional members of the lipocalin family. They are expressed in glands producing mucus for the olfactory and vomeronasal organs. Although their functions remain unclear, they appear to bind small molecules either for presentation to specific receptors, or to remove odorants from the proximity of the receptors to allow detoxification (Miyawaki et al. 1994; Lobel et al. 1998; Steinbrecht 1998). Mouse chromosome X contains a cluster of eight OBP-like lipocalin genes. The syntenic region on human chromosome $\mathrm{X}$ reveals no evidence of a functional OBP-like gene. Rather it contains an OBP-like pseudogene (positions 4463681-4464381 on the April 2003 assembly) almost identical to another pseudogene on the Y chromosome (nucleotides 17822583-17823282). Whereas OBP genes have proliferated and diversified in the rodent lineage, it would appear that they have been lost in the human lineage. This is likely to be associated with the loss of other genes involved in olfaction such as ORs (Gilad et al. 2003; Menashe et al. 2003), V1Rs (Mundy and Cook 2003), and TRPC2 (Wes et al. 1995).

We sought to estimate the effects of evolutionary selection on the potential ligands, receptors, and accessory molecules involved in odorant detection by exploiting the newly sequenced rat and mouse genomes. We infer selection by estimating the ratio of $\mathrm{K}_{\mathrm{A}}$, the number of nonsynonymous substitutions per nonsynonymous site, to $K_{S}$, the number of synonymous substitutions per synonymous site (Miyata and Yasunaga 1980; Yang and Nielsen 2000; Hurst 2002). Typically $K_{A} / K_{S}$ is small $(<0.15)$ for genes subject to purifying selection, whereas for pseudogenes, which are not subject to selection, this ratio relaxes towards 1 . Those genes that contain several sites that have been subject to diversifying selection and rapid amino acid substitution tend to possess higher $K_{A} / K_{S}$ values. In exceptional circumstances, $K_{A} / K_{S}$ values may far exceed 1 , providing unequivocal support for positive diversifying selection.

However, positive selection is often found to be acting on only a few sites, with the majority of sites remaining under purifying selection. In these cases, selection will not necessarily be identified by analyzing gene-averaged $\mathrm{K}_{\mathrm{A}} / \mathrm{K}_{\mathrm{S}}$ values. In order to

Table 2. Relative Accessibility of $\omega^{+}$Residues

\begin{tabular}{|c|c|c|c|c|c|c|c|c|c|c|}
\hline \multirow{2}{*}{$\begin{array}{l}\text { Family } \\
\text { structure (PDB) }\end{array}$} & \multicolumn{2}{|c|}{$\begin{array}{l}\text { LUP } \\
\text { 1CDQ }\end{array}$} & \multicolumn{2}{|c|}{$\begin{array}{l}\text { MUP } \\
\text { 1MUP }\end{array}$} & \multicolumn{2}{|c|}{$\begin{array}{l}\text { OBP } \\
10 B P\end{array}$} & \multicolumn{2}{|c|}{$\begin{array}{l}\text { V2R } \\
\text { 1EWK }\end{array}$} & \multicolumn{2}{|c|}{$\begin{array}{c}\text { MHC M10 } \\
\text { 1BII }\end{array}$} \\
\hline & All & $\boldsymbol{\omega}^{+}$ & All & $\boldsymbol{\omega}^{+}$ & All & $\omega^{+}$ & All & $\boldsymbol{\omega}^{+}$ & All & $\boldsymbol{\omega}^{+}$ \\
\hline Total number of residues & 72 & 15 & 157 & 32 & 158 & 33 & 324 & 8 & 274 & 43 \\
\hline No. buried & 14 & 1 & 40 & 7 & 41 & 3 & 140 & 2 & 74 & 11 \\
\hline No. intermediate & 18 & 4 & 52 & 14 & 59 & 13 & 93 & 3 & 133 & 21 \\
\hline No. exposed & 40 & 10 & 65 & 11 & 58 & 17 & 91 & 3 & 67 & 11 \\
\hline$\%$ buried & 19.4 & 6.7 & 25.5 & 21.9 & 25.9 & 9.1 & 43.2 & 25.0 & 27.0 & 25.6 \\
\hline$\%$ intermediate & 25.0 & 26.7 & 33.5 & 43.8 & 37.3 & 39.4 & 28.7 & 37.5 & 48.5 & 48.8 \\
\hline$\%$ exposed & 55.6 & 66.7 & 41.4 & 34.4 & 36.7 & 51.5 & 28.1 & 37.5 & 24.5 & 25.6 \\
\hline
\end{tabular}

Protein structure information obtained from PDB (www.rcsb.org/pdb/) was selected, and residues corresponding to bound ligands were removed. The accessibility of individual amino acids was determined using DSSP (Kabsch and Sander 1983) and default parameters. Relative accessibility scores were calculated as: relative accessibility = (DSSP score/maximal accessibility of amino acid type) $\times 100$. Results were fractionated into three states: buried ( $<9 \%$ relative accessibility), intermediate (9\%-35\% relative accessibility) and exposed ( $\geq 36 \%$ relative accessibility) (Rost and Sander 1994). The relative accessibility scores for all residues and $\omega^{+}$residues are shown.

\section{Genome Research}

www.genome.org 
identify such instances, sequence data can be fitted to pairs of codon-based substitution models of evolution that either allow or disallow sites with $\mathrm{K}_{\mathrm{A}} / \mathrm{K}_{\mathrm{S}}>1$. Results from such nested models can be compared to provide a statistically significant estimate of their relative likelihood (Yang et al. 1998). The predictive accuracy and power of these methods have been demonstrated by computer simulations (Anisimova et al. 2001, 2002). Their likelihood-ratio tests (LRTs) have been shown to act conservatively, suggesting that predictions are most likely to represent real evolutionary processes, rather than being artifacts of the method. The accessibility of these methods in PAML (Yang 1997) has afforded much opportunity to apply these techniques to biological data. Results have been very encouraging, and the LRT methods implemented in PAML have become well established in predicting sites that have been subject to positive selection (Zanotto et al. 1999; Bishop et al. 2000; Yang et al. 2000b; Peek et al. 2001; Schaner et al. 2001; Yang and Nielsen 2002; Yang and Swanson 2002; Jansa et al. 2003).

Here we used maximum likelihood models of sequence evolution to analyze OR, V1R, and V2R families. We performed a similar analysis on potential extracellular ligands of these receptors (MUPs, LUPs, and OBPs) and MHC class Ib molecules thought to interact with V2Rs (Ishii et al. 2003; Loconto et al. 2003). These analyses predict single codons that are likely to have been subject to positive selection. We interpret the rapid evolution of these sites as indicative of their participation in binding interactions. This method represents the complement of the more usual approach where purifying selection and sequence conservation are harnessed to predict functional sites.

\section{RESULTS}

We performed evolutionary analyses of 16 families of rat and mouse genes that are known to be involved in odorant-mediated G-protein signaling pathways (Table 1). With the exception of the G-protein subunits, each of these families yielded median $\mathrm{K}_{\mathrm{A}} / \mathrm{K}_{\mathrm{S}}$ values that exceed the median $\mathrm{K}_{\mathrm{A}} / \mathrm{K}_{\mathrm{S}}$ value $(0.11)$ for the set of all mouse-rat orthologs (Rat Genome Sequencing Project Consortium 2004). In particular, V1Rs, odorant-binding proteins (OBPs and MUPs $/ \alpha_{2 u}$-globulins) and MHC M10 molecules possess unusually high median $\mathrm{K}_{\mathrm{A}} / \mathrm{K}_{\mathrm{S}}$ values, indicating that they might have been subject to adaptive evolution.

Multiexon genes were predicted from the rat and mouse genome assemblies using hidden Markov models derived from multiple protein sequence alignments and Genewise (Birney and Durbin 2000). This ensures accurate prediction of full-length genes containing the appropriate complement of ex-
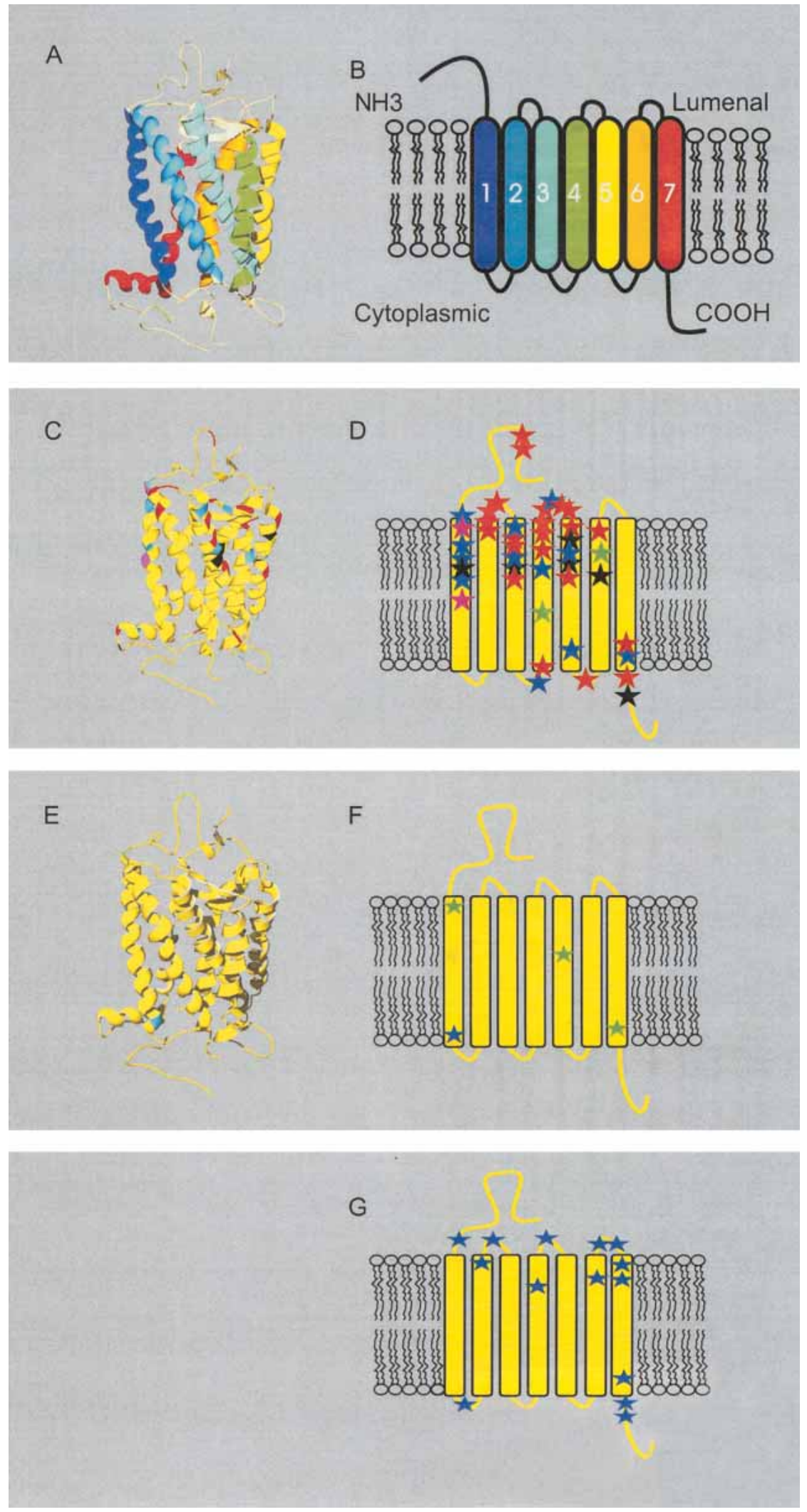

Figure 1 (Legend on next page) 


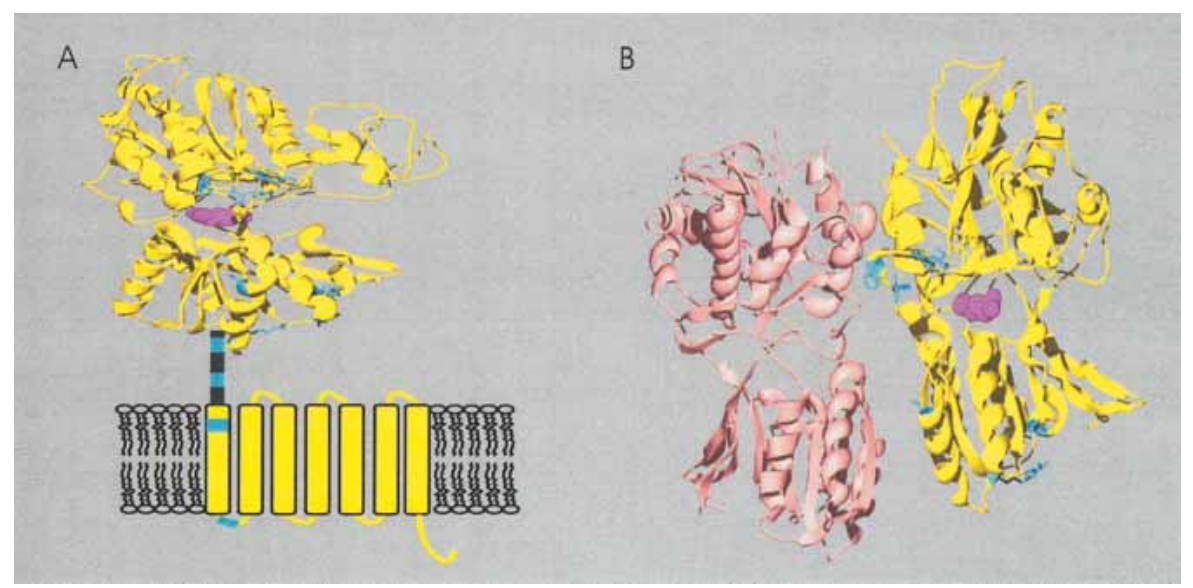

Figure 2 Site-specific $\mathrm{K}_{\mathrm{A}} / \mathrm{K}_{\mathrm{s}}$ analysis for V2Rs. (A) Ribbon diagram showing $\omega^{+}$sites. (B) Representation of the extracellular domain of metabotropic glutamate receptors with mapped $\omega^{+}$sites. Predicted $\omega^{+}$sites are mapped as described in Figure 1 and colored blue. Residues are mapped to the structure of rat metabotropic glutamate receptor subtype 1 complexed with glutamate here colored purple (PDB 1EWK, Kunishima et al. 2000). $\omega^{+}$sites in the carboxy-terminal domain were mapped to the secondary structures of bovine rhodopsin 1EWK (for full details see Suppl. Table 2).

ons where the genome sequence allows. For each family (with the exceptions of OBPs and G-protein subunits), representative genes were chosen by virtue of their involvement in multiple recent gene duplication events. This is because gene duplication is often associated with sequence diversity (Emes et al. 2003), and because it provided sufficient gene numbers for per-codon evolutionary analysis. Detailed analyses of all members of all of these families are beyond the scope of this study. However, our findings that adaptive evolution has occurred to varying extents among the gene sets investigated suggests that adaptive evolution is likely to have acted differentially within and between these families.

With the exception of G-protein subunits, each family was investigated for sites predicted by the codeml algorithm to have been subject to adaptive evolution (see Methods). To ensure consistency of predictions among the different families, only nonconserved alignment positions that were predicted to have been subject to positive selection by one codeml model with a posterior probability $P>0.90$, and by another codeml model with $P>0.50$, were considered (Table 1 ). We will use the term " $\omega^{+}$ sites" to describe these alignment positions. For interpretative purposes, $\omega^{+}$sites have been mapped to homologous positions within representative protein crystal structures using plausible multiple sequence alignments (Supplemental Table 2 available online at www.genome.org). From the fractional solvent accessibility estimates of these sites (Table 2 ) it is evident that $\omega^{+}$sites are underrepresented among buried amino acids, and overrepresented among exposed amino acids. Thus, the majority of these $\omega^{+}$sites are available to participate in binding interactions. We provide multiple alignments, $\omega^{+}$sites, genome coordinates, and gene prediction methodology information in Supplemental Table 2.

\section{Olfactory Receptors}

Approximately 1500 OR genes are present in the mouse genome (Young and Trask 2002), and a similar number is expected in the rat genome. Performing an evolutionary analysis of all sites for all of these genes is prohibitive in terms of computational resources. Consequently, we decided to identify OR genes that have been particularly prone to gene duplication since the divergence of rat and mouse lineages. Using a set of 672 well described mouse ORs and 810 homologous rat genes, we constructed a phylogenetic tree from a matrix of gene pairs' $K_{S}$ values (data not shown). Using a $\mathrm{K}_{\mathrm{S}}$ upper bound of 0.2 , which represents the approximate median $\mathrm{K}_{\mathrm{S}}$ value for 1:1 rat-mouse orthologs (Rat Genome Sequencing Project Consortium 2004), we dissected clades from the tree that contained 10 or more ORs (Table 1). Five such clades were found. Codeml analysis of these five OR families revealed a wide variation in $\omega^{+}$site number, ranging from just two sites for two families, and 9, 14, and 22 sites for the remaining three clades (Fig. 1C,D; Table 1; Supplemental information).

We were interested in analyzing homologs of ORs that are expressed in mammalian testes, as these have been suggested to mediate sperm chemotaxis (Parmentier et al. 1992) and might, therefore, exhibit relatively high evolutionary rates (Branscomb et al. 2000). We collated a set of rat and mouse ORs that are predicted, by synteny and phylogenetic analyses (data not shown), to be orthologous to hOR17-4. This is a human testicular OR that has been shown to mediate chemotaxis activity (Spehr et al. 2003). Four $\omega^{+}$sites were identified among rat genes of this family, of which one was also predicted for mouse genes (Table 1; Fig. 1 E,F).

\section{Vomeronasal Receptors}

We identified $14 \omega^{+}$sites for a set of mouse V1R genes, and their likely rat orthologs, that, when deleted, results in modified behavioral responses (Del Punta et al. 2002). The majority of these sites map to extracellular loops and four of the seven TM regions (Fig. 1G). We then performed a similar analysis of those V2R genes that are the closest homologs to V2R1, the founder member of this family (Ryba and Tirindelli 1997), and identified $12 \omega^{+}$ sites. Because V2Rs contain two distinct structural regions, these sites were mapped to crystal structures either of rat metabotropic glutamate receptor subtype 1 (mGluR1; PDB 1EWK, (Kunishima

Figure 1 Site-specific $\mathrm{K}_{\mathrm{A}} / \mathrm{K}_{\mathrm{S}}$ analysis of olfactory receptors, candidate testis odorant receptors, and V1Rs. $\omega^{+}$codons that were predicted to be under positive selection are mapped to a ribbon representation of the structure of bovine rhodopsin (PDB 1L9H; Okada et al. 2002; for full details see Suppl. Table 2). (A) Ribbon diagram of bovine rhodopsin chain A colored by secondary structure succession. (B) Schematic representation of secondary structures. Ribbon diagram $(C)$ and secondary structure schematic $(D)$ of $\omega^{+}$sites for olfactory receptors. $\omega^{+}$sites predicted for OR family A are highlighted in green, B in black, C in purple, D in blue, and E in red. The analysis of these ORs indicates that positive selection appears to be confined largely to the lumenal half of the molecule. Seventy-five percent of the $\omega^{+}$sites are located in the amino terminal region, extracellular loops, and the extracellular half of the transmembrane helices. Ribbon diagram $(E)$ and secondary structure schematic $(F)$ of $\omega^{+}$sites for the candidate testis-specific odorant receptors (posterior probability $>0.99$, in a single model). Three $\omega^{+}$sites identified when analyzing the rat genes alone are highlighted in green. A single $\omega^{+}$site identified in analysis of both the mouse and rat lineages is highlighted in blue. (G) Schematic of $\omega^{+}$sites for the V1R family (posterior probability $>0.90$ in one model and $>0.5$ in at least one other model) highlighted in blue. The V1R proteins could not be reliably aligned to the rhodopsin sequence, and so positions of $\omega^{+}$sites are relative to published predictions of secondary structures (Dulac and Axel 1995; Ryba and Tirindelli 1997). Swiss-PDBviewer (www.expasy.org/spdbv/; Guex et al. 1999) was used for all structural manipulations, and POVRAY (www.povray.org) was used to generate images. 
et al. 2000) or to the secondary structure of bovine rhodopsin. Eight of the $12 \omega^{+}$sites map to the extracellular mGluR1homologous domain (Fig. 2).

\section{Pheromones and OBPs}

Three lines of evidence strongly suggest that mouse MUPs and rat $\alpha_{2 u}$-globulins arose via separate gene expansions that have been driven by adaptive evolution. First, the topology of the MUP $/ \alpha_{2 u^{-}}$ globulin phylogenetic tree consists of two well separated clades, one specific to mouse MUPs and the other specific to rat $\alpha_{2 u^{-}}$ globulins (data not shown). Second, rat $\alpha_{2 \mathrm{u}}$-globulin, but not mouse MUP, gene duplications have often been accompanied by a 'hitchhiking' zinc finger-pseudogene (Rat Genome Sequencing Project Consortium 2004). Finally, $\alpha_{2 u}$-globulin exonic sequence is less conserved than their intronic sequence (Fig. 3A), again implying rapid coding sequence diversification.

Site-specific analysis of the MUP $/ \alpha_{2 u^{-}}$ globulin family showed strong evidence for positive selection at an exceptionally high proportion of possible sites (32 of 157 sites; Table 1). All but one of these $\omega^{+}$sites map to the surface of the mouse MUP tertiary structure (Bocskei et al. 1992), rather than to its 2-(Sec-butyl) thiazoline-binding pocket (Fig. 3B). This observation is consistent with previous amino acid conservation studies (Darwish Marie et al. 2001). We have also obtained evidence for rat $\alpha_{2 u}$-globulins, but not their MUP counterparts in mouse, that three codons (S69, E79, and F91) have been subject to rat lineage-specific positive selection (Fig. 3B).

Site-specific analysis of OBP genes also predicts a large number of $\omega^{+}$sites (Table 1). Mapping these onto a known crystal structure (1OBP; Bianchet et al. 1996) reveals that the majority of sites are located within the $\beta$-sheets, and project outwards towards the solvent (Fig. 4A). When the 1MUPFamily 5 alignment and 1OBP-Family 6 alignment are superimposed, it is apparent that nine $\omega^{+}$sites are shared by both the MUP and OBP families. Seven of these sites cluster in a region of the 1MUP protein surface, formed by two $\beta$-strands and a loop (Fig. 4B), that is distinct from both its ligand-binding pocket and the OBP dimerization surface (data not shown; Bianchet et al. 1996).

Following the successful identification of high numbers of $\omega^{+}$sites in OBPs, mouse MUPs, and rat $\alpha_{2 \mathrm{u}}$-globulins, our attention was drawn to another family of rodent urinary proteins. Two Ly-6 homologous proteins were originally identified in rat urine (Southan et al. 2002). Mapping their genes to the same region of the rat genome resulted in the identification of a large family of Ly- 6 homologous proteins, which we shall refer to as Ly-6-homologous urinary proteins (LUPs). Investigation of the syntenic regions of mouse and human genomes revealed evolutionary characteristics similar to those seen from MUPs (Fig. 5A). These include independent expansions of LUPs in both rodent genomes and elevated
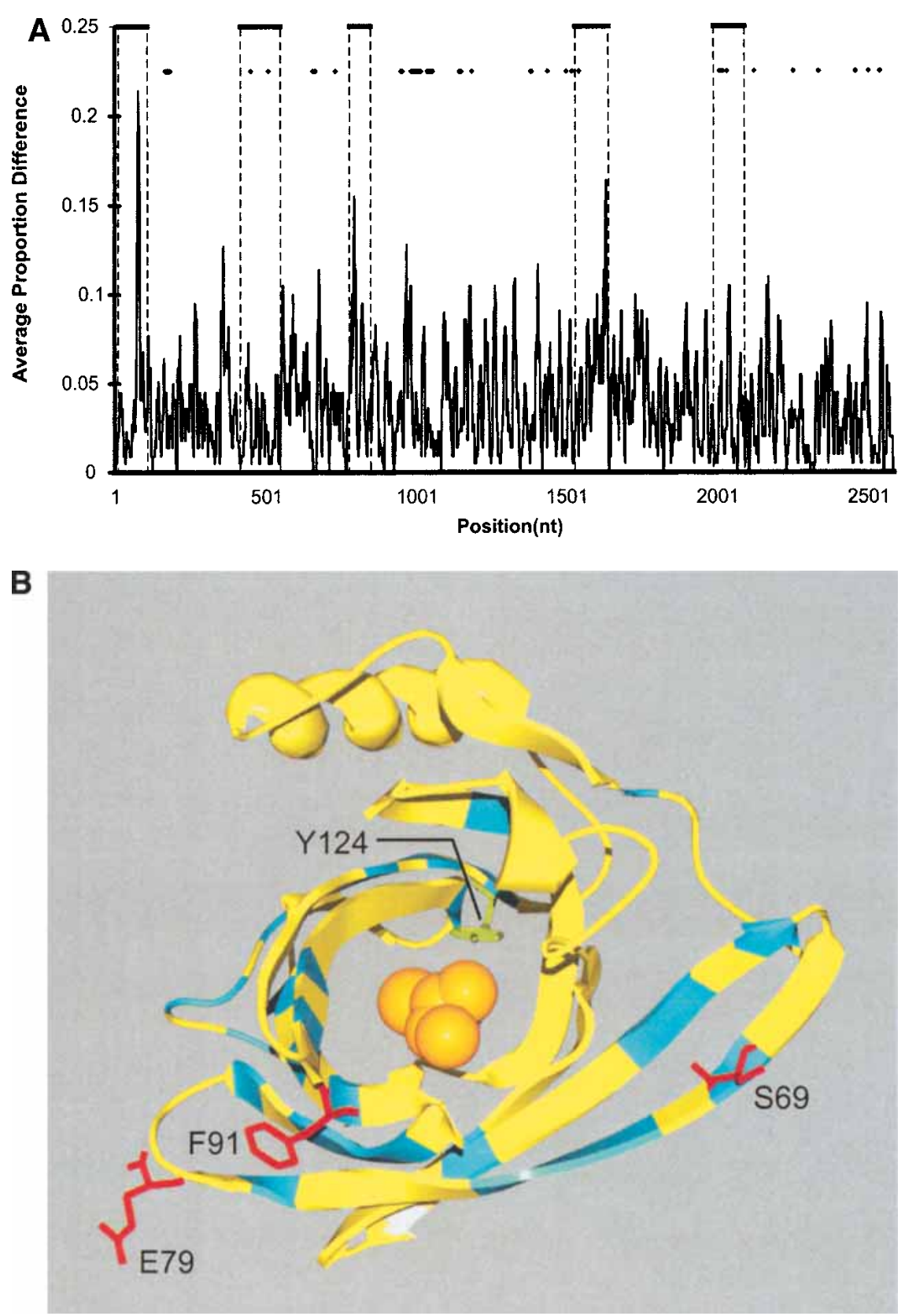

Figure 3 (Legend on next page)
$\mathrm{K}_{\mathrm{A}} / \mathrm{K}_{\mathrm{S}}$ values (Table 1). The phylogenetic tree of LUP sequences indicates that only five rat-mouse-human 1:1:1 orthologous relationships can be resolved (Fig. 5A; data not shown). Of the remaining 22 sequences, eight rat LUP genes appear to have undergone a recent rapid expansion, with only one close mouse relative, and no orthologous human sequence apparent.

Site-specific $\mathrm{K}_{\mathrm{A}} / \mathrm{K}_{\mathrm{S}}$ analysis of this LUP family provided support for positive selection across mouse, human and rat lineages for 25 sites (Table 1; Suppl. Table 1). For more stringent and better-fitting (M2 selection and M3 discrete) models, $15 \omega^{+}$sites were predicted with $P>0.9$ by one codeml model and $P>0.8$ by an additional codeml model. Of these, nine form a cluster on the structure of human complement regulatory protein CD59 (Kieffer et al. 1994), an LUP and Ly-6 homolog (Fig. 5B). A functional role for this region has not yet been proposed. An additional four 
$\omega^{+}$sites map to the opposite face of CD59, which has been shown to be critical for species specificity (Fig. 5B; Zhao et al. 1998).

\section{MHC M1O and G-Protein Subunit Genes}

Analysis of the MHC M10 genes again predicted an exceptionally large number (50) of $\omega^{+}$sites (Table 1). Mapping these sites onto the structure of mouse MHC class I H-2DD, chain A (PDB 1BII; Fig. 6; Achour et al. 1998) shows that 26 of these sites are present in the two $\alpha$-helices of the antigen-binding site. Strikingly, no $\omega^{+}$ sites were detected in the immunoglobulin (IG) domain (Bjorkman et al. 1987b; Achour et al. 1998; see Discussion).

Due to the small number of orthologs known for each of the $G_{\alpha \beta \gamma}$ families relevant to olfaction, site-specific $K_{A} / K_{S}$ analysis was not conducted. However, using yn00 (Yang and Nielsen 2000 ), the gene pair median $K_{A} / K_{S}$ values for $G_{\alpha}, G_{\beta}$, and $G_{\gamma}$ families were found to be $0.028,0.025$, and 0.081 , respectively, which are lower than the median $\mathrm{K}_{\mathrm{A}} / \mathrm{K}_{\mathrm{S}}$ value (0.11) for all 1:1 mouse:rat orthologs (Rat Genome Sequencing Project Consortium 2004). This strongly suggests that G-proteins, including those relevant to odorant signal transduction, have been subject to strong purifying and not diversifying selection.

\section{DISCUSSION}

\section{$\omega^{+}$Sites as Functionally Important Sites}

The inference of function from sequence information frequently assumes that conserved residues are of the greatest functional importance, because these have been subject to strong purifying selection over long periods of evolution (Sander and Schneider 1993; Lichtarge et al. 1996; Mirny and Shakhnovich 1999; Wood and Pearson 1999; Friedberg and Margalit 2002; Madabushi et al. 2002). However, there are two reasons why this approach is not appropriate for genes that evolve rapidly over shorter time periods. First, for orthologs and paralogs that have diverged relatively recently, insufficient time has elapsed for significant sequence divergence due to genetic drift (even for human-mouse alignments, nucleotide identity at selectively neutral sites is high, $\sim 67 \%$ [Waterston et al. 2002]). Thus residue identity is more likely to be due to chance rather than purifying selection.

Secondly, there are reasons to believe that some functionally important sites on rapidly evolving proteins are characterized by amino acid substitution, rather than conservation. Sites that have experienced more unusual and greater numbers of nucleotide substitutions present evidence for adaptive, or Darwinian, selection: Substitutions are fixed in the population more rapidly when advantages accrue to the individual in which they occur (Bock 1980; Golding and Dean 1998; Hughes 1999). Evidence for positive selection implicates these single sites as mediators of function.

\section{Receptors and Positive Selection}

We have obtained evidence for positive selection acting on sites within OR, V1R, and V2R subfamilies, and $\mathrm{MUP} / \alpha_{2 \mathrm{u}}$-globulin and LUP putative pheromone ligands. It is striking that the majority of these $\omega^{+}$sites are solvent-accessible (Table 2) and, for V1Rs and V2Rs, lumenal (10 of $14 \omega^{+}$sites in V1Ra, and 10 of 12 $\omega^{+}$sites in V2Rs, are lumenal). Thus, predicted $\omega^{+}$sites on receptors and their putative extracellular ligands are available to participate in potential receptor-ligand interactions.

The V2R $\omega^{+}$sites form two distinct clusters (Fig. 2). The first of these is within the amino-terminal ligand binding domain (LB1) and forms a cluster with residues involved in dimer formation (Kunishima et al. 2000). Thus, variation of codons at this site may influence the affinities of V2R hetero- or homodimer formation (Fig. 2B). The second cluster lies distant from known ligand binding or dimerization sites in LB2 (Kunishima et al. 2000; Tsuchiya et al. 2002).

Relatively few $\omega^{+}$sites map to the 7TM regions of V1Rs and V2Rs. This contrasts with $72.7 \%$ of $\omega^{+}$sites in the five OR families that lie within TM helices. It is notable that $75.0 \%$ of $\omega^{+}$sites occur within the lumenal half of the OR molecule (the amino-terminal and extracellular loops, and the lumenal halves of TM helices; Fig. 1C,D). This portion of the OR structure is thought to contain the odorant binding pocket within TMs 3-7 (Floriano et al. 2000; Singer 2000; Vaidehi et al. 2002). Two residues K164 (TM4) and F209 (TM5) predicted to bind the ligand in rat OR-17 (Singer 2000) are predicted $\omega^{+}$sites for at least one of the OR families analyzed here. Additional $\omega^{+}$sites lie close to TM3 residues which influence ligand binding (Vaidehi et al. 2002). Thus, the receptors' $\omega^{+}$sites predicted in this study represent excellent candidates for mediating ligand interactions.

For ORs (Fig. 1 C-F), V1Rs (Fig. 1G), and V2Rs (Fig. 2), $\omega^{+}$ sites were predicted at cytoplasmic regions of TMs 1 and 7, which spatially cluster in three dimensions (Fig. 1A). G-proteins are thought to bind GPCRs following a conformational change involving TM7 (for review, see Filipek et al. 2003). The clustering of $\omega^{+}$sites at the TM1 and TM7 cytoplasmic surface of these GPCRs thus suggests that these sites may bind G-protein subunits. However, it is notable that we find no evidence for positive selection and gene duplication of G-protein subunit genes. Thus, the rapidity of sequence change within these receptors' sites might have arisen from adaptive requirements for higher association or dissociation constants with their cognate G-proteins.

Figure 3 (A) Sequence divergence of rat $\alpha_{2 u}$-globulin genes and pseudogenes. Genomic DNA from 22 rat $\alpha_{24}$-globulin genes, including 12 suspected of being pseudogenes, identified as described in Methods. Nucleotide sequences were highly conserved (mean $93 \% \pm 2 \%$ identity calculated from ungapped columns), and were aligned using HMMer (Eddy 1998) with manual adjustments. The proportion difference was calculated as the fraction of nucleotides in each column that differ from the consensus nucleotide. The average proportion difference from a sliding window of $10 \mathrm{nt}$ is plotted against initial nucleotide position. Alignment columns with $>50 \%$ gaps are shown as diamonds and were ignored for these calculations. Exons are shown as solid horizontal lines, with intron-exon boundaries defined by dashed vertical lines. (B). Site-specific $\mathrm{K}_{\mathrm{A}} / \mathrm{K}_{\mathrm{S}}$ analysis of the MUP/ $/ \alpha_{2 u}$-globulin family, lipocalin homologs. $\omega^{+}$codons with a posterior probability $>0.90$ by one codeml model, and $>0.5$ by at least one other model, are shown mapped to the crystal structure of murine MUP complexed with 2-(Sec-butyl) thiazoline (PDB 1MUP; Bocskei et al. 1992). Residues corresponding to $\omega^{+}$codons are highlighted in blue; 2-(Sec-butyl) thiazoline is shown in orange. A single interior $\omega^{+}$site corresponds to 1MUP:Y124 (shown in green). Although there are no data available to support a direct role in binding, this tyrosine residue neighbors, and has a similar orientation to, 1MUP:R126, which is required for thiazoline-binding (Bocskei et al. 1992). Y124 is as close to 2-(Sec-butyl) thiazoline as 1MUP:F60, a proposed ligand-binding residue (Darwish Marie et al. 2001). All mouse, and most rat, sequences contain a tyrosine in the position equivalent to 1MUP:Y124. However, two rat genes (mup_rn11 and mup rn20) possess substitutions (to leucine and tryptophan, respectively) that might modify the geometry of the internal ligand-binding cavity. Consequently, these two genes might have evolved either to bind a ligand different from those of their paralogs, or else the same ligand with a different affinity. We also identified three codons (1MUP:S69, E79, and F91) that have been subject to rat lineage-specific positive selection. These are shown here in ball-and-stick format and colored red. These sites are the only alignment positions where amino acid substitutions are not conserved in rat $\alpha_{2 u}$-globulins but are conserved in mouse MUPs. One rat $\alpha_{2 u}$-globulin (mup_rn5) possesses unusual substitutions at all three positions (for S69, two substitutions at second and third codon positions $[R \rightarrow T]$; for $E 79$, a first position transversion $[\mathrm{P} \rightarrow \mathrm{A}]$; and for $\mathrm{F91}$, a second position transition $\mathrm{G} \rightarrow \mathrm{E}$ ). mup_rn18 shares the $\mathrm{R} \rightarrow \mathrm{T}$ substitution at $\mathrm{S} 69$ with mup_rn18. This suggests that at least three sites in $\alpha_{24}$-globulins may be under positive selection in the rat lineage alone, possibly reflecting the functional divergence of two genes (mup_rn5 and mup_rn18) from the other rat paralogs. 

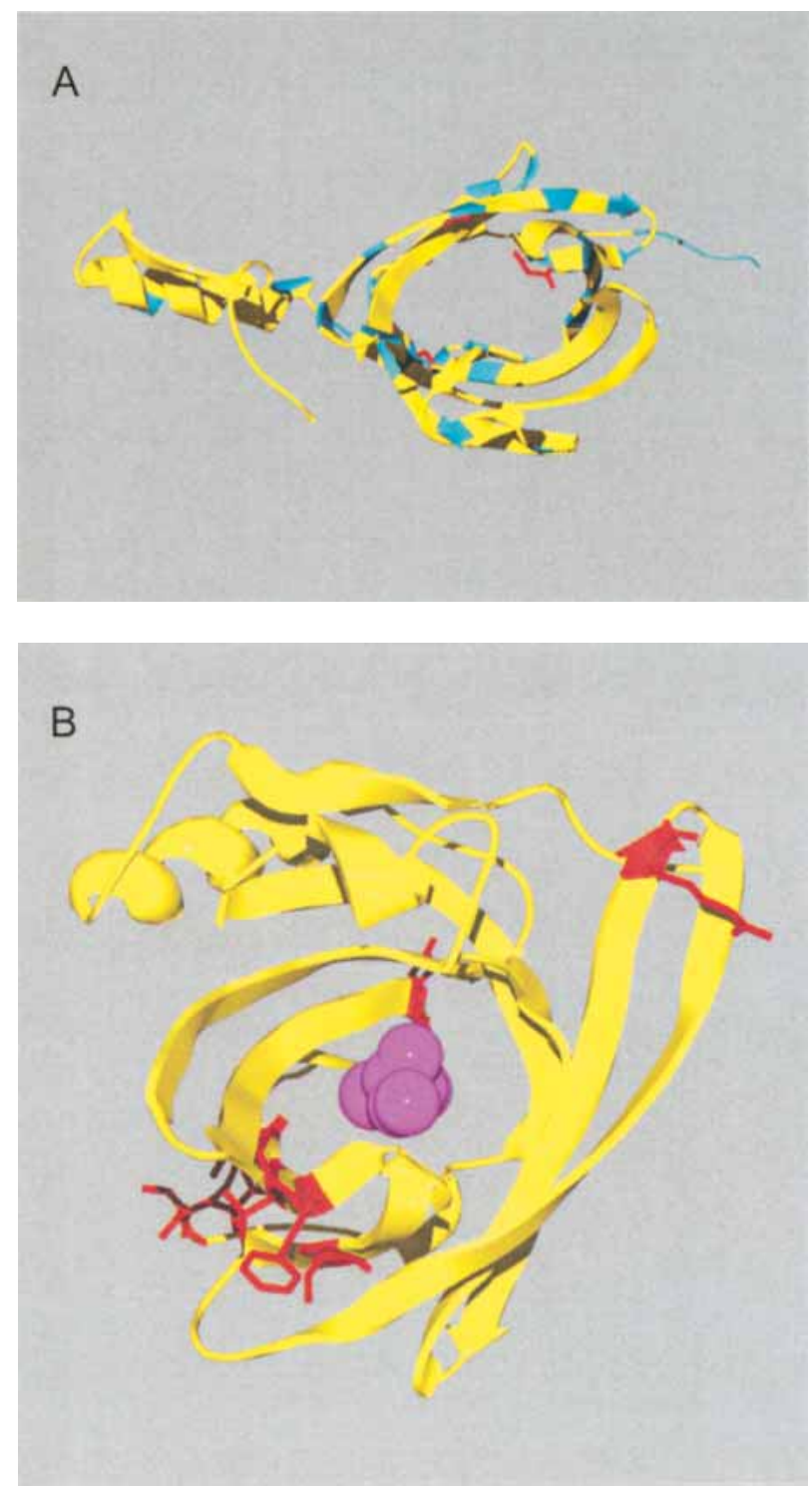

Figure 4 (A) Site-specific $\mathrm{K}_{\mathrm{A}} / \mathrm{K}_{\mathrm{S}}$ analysis of OBPs. $\omega^{+}$codons with a posterior probability $>0.90$ by one codeml model, and $>0.5$ by at least one other model, were mapped to the crystal structure of cow OBP (PDB: 1OBP; Bianchet et al. 1996) and colored blue. Three $\omega^{+}$site side-chains, shown in ball-and-stick format and colored red, are predicted to project into the interior of the OBP $\beta$-barrel. Two of these side-chains (1OBP:T38 and V69) are within $5 \AA$ of the ligand that was cocrystalized in the 1OBP $\mathrm{X}$-ray structure, whereas the third side-chain (1OBP:E84) is more distant from the ligand $(\sim 8 \AA)$, and closer to the cavity edge. (B) Positively selected sites shared by both MUP $/ \alpha_{2 u}$-globulins and OBPs. A multiple alignment of MUP $/ \alpha_{2 u^{-}}$-globulins and OBPs was used to identify nine $\omega^{+}$ codons shared by both families. These sites are spatially clustered and therefore represent a hypervariable region likely to be important for functional diversity. The nine $\omega^{+}$codons were mapped to the crystal structure of mouse MUPs (PDB 1MUP) and are colored red. 2-(Sec-butyl) thiazoline is shown in purple.

\section{Ligands and Positive Selection}

External residues are also overrepresented among $\omega^{+}$sites in putative pheromones (Table 2), and thus these may represent possible binding sites. Only one $\omega^{+}$site occurs within the interior of MUPs that may participate in binding the volatile odorant (Fig. 3B; Timm et al. 2001). The identification of these $\omega^{+}$sites should assist in teasing apart the pheromonal functions of MUPs. Both the MUP protein without a bound ligand, and a recombinant MUP have pheromone activities (Mucignat-Caretta et al. 1995; Hurst et al. 2001). Moreover, a rat $\alpha_{2 u}$-globulin lacking a ligand induces the activation of $\mathrm{G}_{\mathrm{O}}$, a G-protein that is coexpressed with V2Rs in the basal half of the VNO neuroepithelium (Krieger et al. 1999). This strongly suggests that mouse MUPs and rat $\alpha_{2 u^{-}}$ globulins bind V2Rs, and that $\omega^{+}$sites in MUPs $/ \alpha_{2 u^{-}}$-globulins and V2Rs might participate in these MUP-V2R and $\alpha_{2 \mathrm{u}}$-globulin-V2R heterodimeric interactions. A V1R is known to bind 2-heptanone (Boschat et al. 2002), whose analog is a volatile ligand for MUPs (Timm et al. 2001). Thus, each component of the odorant-MUP/ $\alpha_{2 u}$-globulin complex may be recognized by one of the two VNO receptor types: the odorant by V1Rs and the MUP/ $\alpha_{2 \mathrm{u}}$-globulin by V2Rs.

We also investigated LUPs whose members, like MUPs, are expressed in the male rat liver (evidence from EST BQ094064), and are not known to be expressed in females. Like MUPs they possess the unusual property of being present at high levels in male rat urine (Southan et al. 2002). Moreover, their rapid sequence diversification, pseudogenization and gene duplication in rodents mirror those seen for MUPs and are strong evidence for adaptive evolution. Together, the evolutionary and expression similarities between MUPs and LUPs, and their unusually high concentrations in urine, suggest to us that these two families of proteins possess comparable functions. Consequently, we suggest that rodent LUPs, like MUPs, may be pheromones which contain hypervariable solvent-accessible binding sites.

\section{MIOs and Positive Selection}

We identified $50 \omega^{+}$sites in MHC M10 genes. M10s are nonclassical class I MHC molecules which possess a comparable structure to class 1 heavy chains. The class I heterodimer consists of the heavy chain, containing a peptide-binding domain and an IG domain, and a $\beta 2$-microglobulin light chain. M10s are not known to possess immunity functions comparable to those of classical class I MHC molecules, but the finding that $\beta 2$ microglobulin is required for the cell surface expression of M10s argues that the molecular functions of nonclassical and classical class I MHC molecules are highly similar.

Twenty-six of the $50 \omega^{+}$sites are located within the two $\alpha$-helices that, in class 1 molecules, form the peptide-binding groove. For class 1 molecules those residues that bind antigen, and others that bind a T-cell receptor (TCR), have been determined (Bjorkman et al. 1987a). Four $\omega^{+}$sites in $\alpha$-helix 1, and six in $\alpha$-helix 2, map to predicted TCR-binding residues, whereas seven $\omega^{+}$sites in $\alpha$-helix 1 , and four in $\alpha$-helix 2 , are located in the equivalent antigen-binding site (Fig. 6). M10s appear, from their high propensities of gene duplication and sequence diversification, to have been subject to strong adaptive constraints during their recent evolution. Selection appears to have driven sequence diversity within a peptide-binding site of M10s, in a similar manner to that of classical class 1 molecules (Hughes and Nei 1988; Swanson et al. 2001).

Several functional roles have been proposed for M10s (Dulac and Torello 2003; Ishii et al. 2003; Loconto et al. 2003). M10s as accessory molecules in V2R-mediated pheromone recognition does not account for the exceptionally strong adaptive evolution that we have observed. As pheromone recognition itself is well described for V2Rs only, this leaves a role for M10s in binding protein pheromones during their cellular internalization, which we assume is necessary for VNO detoxification. These observations contribute to the ongoing debate regarding whether the MHC mediates pheromone-recognition events and odorantinduced behavior (Singh et al. 1987; Potts et al. 1991; Schaefer et al. 2001). 


\section{Selective Pressures}

Underlying the positive selective pressures exerted on these pheromone and odorant receptors is competition among individuals. Interspecific competition in terms of foraging and predator avoidance may have driven OR sequence diversification and

A

Rat Chromosome 8
5 ,

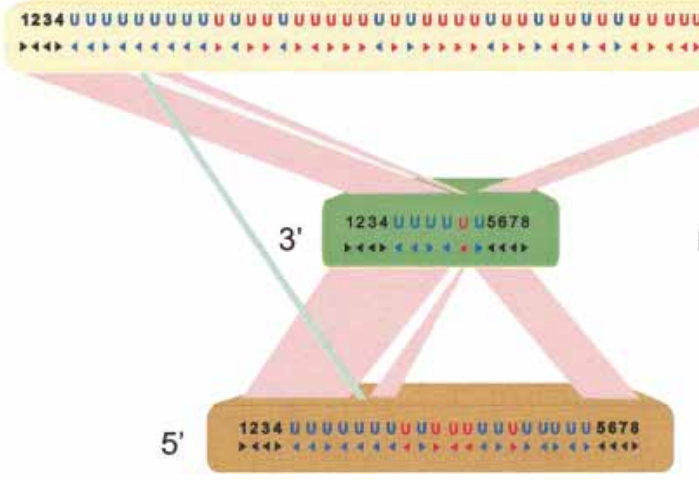

gene duplication. Conspecific competition, however, such as among adults for mate selection (Alley 1982; Bolnick et al. 2003), or among siblings for sustenance (Stockley and Parker 2002), may have acted on all other genes considered in the present study. This is because olfactory cues are costly in terms of fitness (Gosling et al. 2000), and have been implicated in individual recognition (mediated by MUPs; Hurst et al. 2001) and sexual behavior (Lee and van der Boot 1955; Whitten 1958; Bruce 1968; Vandenbergh 1976, 1989; Ma et al. 1998; Novotny et al. 1999), and thus provide a potent mechanism for sexual selection. We hypothesize that conspecific competition has resulted in the propagation, within rodent populations, of pheromones that are well adapted to their receptors, and receptors that are well adapted to their pheromones. Adaptations consequently involve amino acids situated at the interface between pheromone and receptor, and these are represented among the $\omega^{+}$sites identified in this study. This hypothesis is well suited to experimental investigation by molecular, site-directed mutagenesis, and ethological studies.

\section{METHODS}

\section{Sequence Data Collection}

\section{Mouse and Rat Olfactory Receptors}

GenBank identifiers of predicted full-length mouse olfactory receptors were obtained from ORDB, a database of olfactory receptors (Crasto et al. 2002). Subsequently, the corresponding DNA sequences were mapped to the mouse genome (Feb 2002 mmbuild2) and known Ensembl (Hubbard et al. 2002) mouse genes using BLAT, default parameters and a minimum acceptance threshold of $95 \%$ sequence identity over 40 nucleotides (Kent 2002) at the UCSC genome browser (http://genome. ucsc.edu/). The corresponding protein sequences of these genes were multiply aligned using CLUSTAL W (Thompson et al. 1994) and edited manually to minimize gap positions. Sequences that appeared to be incomplete were removed from the alignment. Orthologous rat genes were then obtained using relationships available from Ensembl's Compara database (Clamp et al. 2003).

Figure 5 (A) Gene order of Ly-6 homologous urinary protein (LUP) genes. Syntenic regions of mouse chromosome 9 (February 2003 assembly), human chromosome 11 (November 2002 assembly), and rat chromosome 8 (June 2003 assembly) are shown, approximately to scale. Genes are indicated in blue letters, and pseudogenes in red. Strand orientation is indicated by arrowheads. Homologous rat-mouse-human relationships are represented by pink lines. A single mouse-rat homologous relationship that does not have a detectable human counterpart is represented by a green line. Numbers represent genes not homologous to LUPs: 1, BOC an immunoglobulin superfamily member; 2, DEAD box polypeptide 25; 3, FLJ32915 hypothetical protein; 4, pseudouridine synthase 3; 5, checkpoint kinase 1; 6, oligosaccharyl transferase STT3 subunit (B5); 7, P53-induced protein 8; and 8, zygin I. LUP genes and pseudogenes scored greater than 0 bits using GeneWise, default parameters [excepting a substitution error rate (subs) of 0.1], and a hidden Markov model of LUP homologs' amino acid sequences. Pseudogenes, as opposed to genes, were assigned on the basis of incomplete sequences, frameshifts and in-frame stop codons. ( $B$ ) Sitespecific $\mathrm{K}_{\mathrm{A}} / \mathrm{K}_{\mathrm{S}}$ analysis of LUP homologs. $\omega^{+}$codons with a posterior probability $>0.80$ by at least two codeml models are mapped to the NMR structure of human CD59 (PDB 1CDQ; Kieffer et al. 1994). Residues corresponding to $\omega^{+}$codons are highlighted in blue. Several residues that have been experimentally shown to be important for species selectivity of human CD59 (i.e., H44, N48, D49, T51, T52, R55, and E58; Zhao et al. 1998) are shown in green.

\section{Vomeronasal Receptors, MUPs, LUPs, OBPs, MHC-M10, and G-Proteins}

Families of genes were collected for further analysis using a protocol of gene identification, mapping of the gene to the genome, and gene building (Suppl. Table 2). Briefly, a starting gene set was identified containing either known reference sequences or else homologs identified by database searching. The gene set was then mapped to the relevant genome via EnsMart (http://www. ensembl.org/EnsMart/) or BLAT and the UCSC genome browser. To obtain fulllength gene predictions, genomic DNA in the region of the mapped genes was then

\section{Genome Research}

www.genome.org 


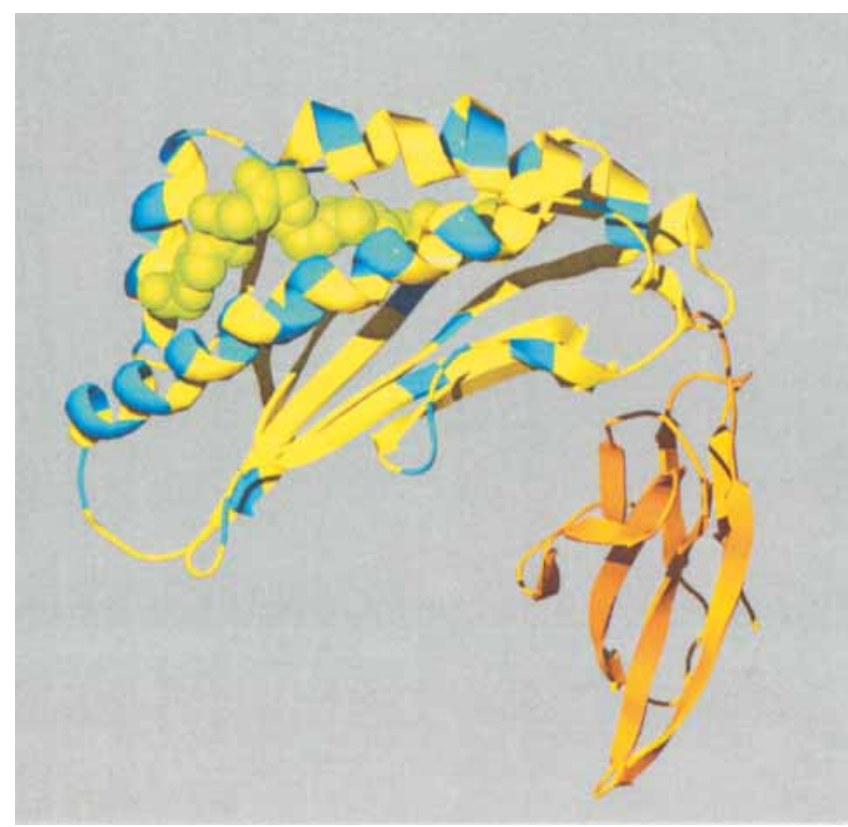

Figure 6 Site-specific $\mathrm{K}_{\mathrm{A}} / \mathrm{K}_{\mathrm{S}}$ analysis of MHC-M10 genes. Codons that were predicted to be under positive selection with a posterior probability $>0.90$ by one codeml model, and $>0.5$ by at least one other model, are mapped to the crystal structure of mouse MHC class I H-2DD, chain: $A$ in complex with the HIV-1 derived peptide p18-110, shown in green (PDB identifier 1BII (Achour et al. 1998). $\omega^{+}$sites, shown in blue, are predominantly located along the $\alpha$-helices of the peptide recognition region. No $\omega^{+}$sites were mapped to the immunoglobulin domain of the protein, shown here in orange.

used as a target for gene prediction using GeneWise (Birney and Durbin 2000). The initial step of gene mapping using BLAT dramatically reduces the search space for the gene building programs, adding greater reliability in gene prediction. For OBPs, identified protein sequences were used in a PSI-BLAST search (Altschul et al. 1997) to obtain likely orthologs from species other than mouse and rat. G-protein- $\alpha, \beta$, and $\gamma$ sequences were obtained by text searching EnsMart at Ensembl (http://www. ensembl.org/EnsMart/). FASTA-formatted sequence files, alignments, and trees for each family are available as Supplemental information.

The solvent accessibility of $\omega^{+}$residues was calculated using structural information from PDB (http://www.rcsb.org/pdb/). For each structure, any ligand was removed prior to accessibility score prediction using the DSSP algorithm (Kabsch and Sander 1983). Relative accessibility scores were produced by dividing by amino acid-specific maximal accessibility values. These scores were fractionated into three states: buried $(<9 \%$ relative accessibility), intermediate (9\%-35\% relative accessibility), and exposed ( $\geq 36 \%$ relative accessibility), as described (Rost and Sander 1994).

\section{Estimation of Evolutionary Rates and Orthology Relationships}

Evolutionary rates were estimated for all gene pairs in each of the 16 families. When multiple transcripts were predicted for a single gene, the longest transcript was used. The corresponding DNA sequences were aligned according to the amino acid multiple alignment. All pairs of these sequences were extracted from the multiple alignments and used to calculate values of $\mathrm{K}_{\mathrm{A}}$ and $\mathrm{K}_{\mathrm{S}}$ using yn00 (Yang and Nielsen 2000) and default parameters.

\section{Site-Specific $\mathrm{K}_{\mathrm{A}} / \mathrm{K}_{\mathrm{S}}$ Analysis}

Site-specific $\mathrm{K}_{\mathrm{A}} / \mathrm{K}_{\mathrm{S}}$ analysis was carried out using codeml, an application from the PAML package (v1.31) of phylogenetic soft- ware for applying different models of evolution to sequences (Yang 1997). For each analysis, cDNA sequences were collected as described previously. Phylogenetic trees were constructed from the $K_{\mathrm{S}}$ matrices by the neighbor-joining algorithm implemented in the PHYLIP Neighbor application (Felsenstein 1989). In order to ensure that the site-specific $\mathrm{K}_{\mathrm{A}} / \mathrm{K}_{\mathrm{S}}$ analysis was not influenced by sites with a large number of gaps, all columns with gaps in greater than $25 \%$ of the sequences were removed from the cDNA alignment. The $\mathrm{K}_{\mathrm{s}}$-derived tree file and alignment were used as input files for codeml. Codeml uses maximum likelihood to predict sites in a group of cDNA sequences that have been subject to positive selection. Simple models where sites are predicted to have a $K_{A} / K_{S}$ or $\omega$ ratio between 0 and 1 can be compared with more complex models that also allow for ratios that are greater than 1 . Log likelihood values $(l)$ are calculated for each model by maximum likelihood. This enables a likelihood ratio test (LRT) to be used to provide a statistically significant comparison between a simple model, and a more complex nested model. If the complex model indicates an estimated $\omega$ ratio that is greater than 1 , and the test statistic $(2 \Delta l)$ is greater than critical values of the Chi square $\left(\chi^{2}\right)$ distribution with the appropriate degree of freedom (Yang et al. 1998), then positive selection can be inferred. Bayesian probabilities are used to predict which sites (codons) from the original data are most likely to have been under positive selection. We used three pairs of simple and complex models: M0 (one-ratio; Goldman and Yang 1994) versus M3 (discrete; Yang et al. 2000a); M1 (neutral) versus M2 (selection; Nielsen and Yang 1998); and M7 ( $\beta$ ) versus M8 ( $\beta+\omega$; Yang et al. $2000 a)$. M0 allows a single per-site $\omega$ value for all sequences, which is allowed to vary between 0 and 1 , whereas M3 attempts to fit the data to three $\omega$ values estimated from the data. M1 allows an $\omega$ value of 0 or 1, whereas M2 allows an additional site class which is estimated from the data. M7 attempts to fit the data to a beta distribution of $\omega$ values between 0 or 1 , with 10 site classes, whereas M8 allows an additional site class which is estimated from the data. According to previous studies, these tests are of increasing stringency, with M8 having the most statistical power, and M3 the least (Anisimova et al. 2002). The M0/M3 LRT is compared to $\chi^{2}$ with four degrees of freedom (df), whereas both the M1/M2 and M7/M8 LRTs have two df; the latter two pairs thus possess a greater statistical power. Consequently, predictions by $\mathrm{M} 0 / \mathrm{M} 3$ alone should be viewed with caution in the absence of corroborating evidence from other model pairs. It was previously noted that the iterative estimation of $\omega$ values by both M2 and M8 are susceptible to local minima. This has the result that the most likely numerical solutions may not always be found (http:// abacus.gene.ucl.ac.uk/software/paml.html). To circumvent this problem, we initiated M2 and M8 codeml runs with different initial $\omega$ values $(\omega=0.03,0.3$, and 1.3$)$, and present here only those results with the greatest log likelihood values.

\section{Protein Structure Analysis}

Representative protein tertiary structures were chosen for each gene family based on the most similar sequence for which a crystal structure is available (Table 2). The amino acid sequence corresponding to the chosen structure was aligned to the family alignment using HMMer or BLAST, depending on the degree of similarity, and manually adjusted to ensure conservation of secondary structure elements. Consistency between different evolutionary models was taken into account, so that, where appropriate, only nonconserved alignment positions predicted to be under positive selection with a posterior probability $>0.90$ by one codeml model (i.e., M2, M3, or M8), and $>0.50$ by at least one other model, were highlighted. We have termed these alignment positions " $\omega^{+}$sites". Swiss-PDBviewer (www.expasy.org/spdbv/; Guex et al. 1999) was used for all structural manipulations, and POVRAY (www.povray.org) was used to generate images.

\section{ACKNOWLEDGMENTS}

We thank Eitan Winter, and other CPP group members, for helpful discussions, and Prof. Ziheng Yang for advice. We also thank Ensembl, George Weinstock, and the Rat Genome Sequencing 
Project Consortium for valuable assistance. This work was funded by the UK Medical Research Council. S.A.B. is supported by a Royal Commission for the Exhibition of 1851 Fellowship.

The publication costs of this article were defrayed in part by payment of page charges. This article must therefore be hereby marked "advertisement" in accordance with 18 USC section 1734 solely to indicate this fact.

\section{REFERENCES}

Achour, A., Persson, K., Harris, R.A., Sundback, J., Sentman, C.L., Lindqvist, Y., Schneider, G., and Karre, K. 1998. The crystal structure of H-2Dd MHC class I complexed with the HIV-1-derived peptide P18-I10 at $2.4 \AA$ A resolution: Implications for T cell and NK cell recognition. Immunity 9: 199-208.

Adkins, R.M., Gelke, E.L., Rowe, D., and Honeycutt, R.L. 2001. Molecular phylogeny and divergence time estimates for major rodent groups: Evidence from multiple genes. Mol. Biol. Evol. 18: $777-791$.

Alley, T.R. 1982. Competition theory, evolution, and the concept of an ecological niche. Acta Biotheor. 31: 165-179.

Altschul, S.F., Madden, T.L., Schaffer, A.A., Zhang, J., Zhang, Z., Miller, W., and Lipman, D.J. 1997. Gapped BLAST and PSI-BLAST: A new generation of protein database search programs. Nucleic Acids Res. 25: $3389-3402$.

Anisimova, M., Bielawski, J.P., and Yang, Z. 2001. Accuracy and power of the likelihood ratio test in detecting adaptive molecular evolution. Mol. Biol. Evol. 18: 1585-1592.

. 2002. Accuracy and power of bayes prediction of amino acid sites under positive selection. Mol. Biol. Evol. 19: 950-958.

Bianchet, M.A., Bains, G., Pelosi, P., Pevsner, J., Snyder, S.H., Monaco, H.L., and Amzel, L.M. 1996. The three-dimensional structure of bovine odorant binding protein and its mechanism of odor recognition. Nat. Struct. Biol. 3: 934-939.

Birney, E. and Durbin, R. 2000. Using GeneWise in the Drosophila annotation experiment. Genome Res. 10: $547-548$.

Bishop, J.G., Dean, A.M., and Mitchell-Olds, T. 2000. Rapid evolution in plant chitinases: Molecular targets of selection in plant-pathogen coevolution. Proc. Natl. Acad. Sci. 97: 5322-5327.

Bjorkman, P.J., Saper, M.A., Samraoui, B., Bennett, W.S., Strominger, J.L., and Wiley, D.C. 1987a. The foreign antigen binding site and T cell recognition regions of class I histocompatibility antigens. Nature 329: $512-518$

-1987b. Structure of the human class I histocompatibility antigen, HLA-A2. Nature 329: 506-512.

Bock, M.J. 1980. The definition and recognition of biological adaptation. Am. Zool. 20: 217-227.

Bocskei, Z., Groom, C.R., Flower, D.R., Wright, C.E., Phillips, S.E., Cavaggioni, A., Findlay, J.B., and North, A.C. 1992. Pheromone binding to two rodent urinary proteins revealed by X-ray crystallography. Nature 360: 186-188.

Bolnick, D.I., Svanback, R., Fordyce, J.A., Yang, L.H., Davis, J.M., Hulsey, C.D., and Forister, M.L. 2003. The ecology of individuals: Incidence and implications of individual specialization. Am. Nat. 161: 1-28

Boschat, C., Pelofi, C., Randin, O., Roppolo, D., Luscher, C., Broillet, M.C., and Rodriguez, I. 2002. Pheromone detection mediated by a V1r vomeronasal receptor. Nat. Neurosci. 5: 1261-1262.

Branscomb, A., Seger, J., and White, R.L. 2000. Evolution of odorant receptors expressed in mammalian testes. Genetics 156: 785-797.

Briand, L., Huet, J., Perez, V., Lenoir, G., Nespoulous, C., Boucher, Y., Trotier, D., and Pernollet, J.C. 2000. Odorant and pheromone binding by aphrodisin, a hamster aphrodisiac protein. FEBS Lett. 476: $179-185$.

Bruce, H.M. 1968. Absence of pregnancy-block in mice when stud and test males belong to an inbred strain. J. Reprod. Fertil. 17: 407-408.

Cavaggioni, A. and Mucignat-Caretta, C. 2000. Major urinary proteins, $\alpha(2 \mathrm{U})$-globulins and aphrodisin. Biochim. Biophys. Acto 1482: $218-228$.

Cavasotto, C.N., Orry, A.J., and Abagyan, R.A. 2003. Structure-based identification of binding sites, native ligands and potential inhibitors for G-protein coupled receptors. Proteins 51: 423-433.

Clamp, M., Andrews, D., Barker, D., Bevan, P., Cameron, G., Chen, Y., Clark, L., Cox, T., Cuff, J., Curwen, V., et al. 2003. Ensembl 2002: Accommodating comparative genomics. Nucleic Acids Res. 31: 38-42.

Crasto, C., Marenco, L., Miller, P., and Shepherd, G. 2002. Olfactory Receptor Database: A metadata-driven automated population from sources of gene and protein sequences. Nucleic Acids Res. 30: $354-360$

Darwish Marie, A., Veggerby, C., Robertson, D.H., Gaskell, S.J., Hubbard, S.J., Martinsen, L., Hurst, J.L., and Beynon, R.J. 2001. Effect of polymorphisms on ligand binding by mouse major urinary proteins.
Protein Sci. 10: $411-417$

Del Punta, K., Leinders-Zufall, T., Rodriguez, I., Jukam, D., Wysocki, C.J., Ogawa, S., Zufall, F., and Mombaerts, P. 2002. Deficient pheromone responses in mice lacking a cluster of vomeronasal receptor genes. Nature 419: 70-74.

Dulac, C. and Axel, R. 1995. A novel family of genes encoding putative pheromone receptors in mammals. Cell 83: 195-206.

Dulac, C. and Torello, A.T. 2003. Molecular detection of pheromone signals in mammals: From genes to behaviour. Nat. Rev. Neurosci. 4: $551-562$.

Eddy, S.R. 1998. Profile hidden Markov models. Bioinformatics 14: $755-763$.

Emes, R.D., Goodstadt, L., Winter, E.E., and Ponting, C.P. 2003. Comparison of the genomes of human and mouse lays the foundation of genome zoology. Hum. Mol. Genet. 12: 701-709.

Felsenstein, J. 1989. PHYLIP-Phylogeny inference package. Cladistics 5: $164-166$.

Filipek, S., Teller, D.C., Palczewski, K., and Stenkamp, R. 2003. The crystallographic model of rhodopsin and its use in studies of other $G$ protein-coupled receptors. Annu. Rev. Biophys. BioMol. Struct. 32: 375-397.

Floriano, W.B., Vaidehi, N., Goddard III, W.A., Singer, M.S., and Shepherd, G.M. 2000. Molecular mechanisms underlying differential odor responses of a mouse olfactory receptor. Proc. Natl. Acad. Sci. 97: 10712-10716

Flower, D.R. 1996. The lipocalin protein family: Structure and function. Biochem. J. 318 (Pt 1): 1-14.

Friedberg, I. and Margalit, H. 2002. Persistently conserved positions in structurally similar, sequence dissimilar proteins: Roles in preserving protein fold and function. Protein Sci. 11: 350-360.

Gilad, Y., Man, O., Paabo, S., and Lancet, D. 2003. Human specific loss of olfactory receptor genes. Proc. Natl. Acad. Sci. 100: 3324-3327.

Glusman, G., Yanai, I., Rubin, I., and Lancet, D. 2001. The complete human olfactory subgenome. Genome Res. 11: 685-702.

Golding, G.B. and Dean, A.M. 1998. The structural basis of molecular adaptation. Mol. Biol. Evol. 15: 355-369.

Goldman, N. and Yang, Z. 1994. A codon-based model of nucleotide substitution for protein-coding DNA sequences. Mol. Biol. Evol. 11: $725-736$.

Gosling, L.M., Roberts, S.C., Thornton, E.A., and Andrew, M.J. 2000. Life history costs of olfactory status signalling in mice. Behav. Ecol. Sociobiol. 48: $328-332$.

Guex, N., Diemand, A., and Peitsch, M.C. 1999. Protein modelling for all. Trends Biochem. Sci. 24: 364-367.

Hermans, E. and Challiss, R.A. 2001. Structural, signalling and regulatory properties of the group I metabotropic glutamate receptors: Prototypic family C G-protein-coupled receptors. Biochem. J. 359: 465-484

Hubbard, T., Barker, D., Birney, E., Cameron, G., Chen, Y., Clark, L., Cox, T., Cuff, J., Curwen, V., Down, T., et al. 2002. The Ensembl genome database project. Nucleic Acids Res. 30: 38-41.

Hughes, A.L. 1999. Adaptive evolution of genes and genomes. Oxford University Press, New York.

Hughes, A.L. and Nei, M. 1988. Pattern of nucleotide substitution at major histocompatibility complex class I loci reveals overdominant selection. Nature 335: 167-170

Hurst, J.L., Payne, C.E., Nevison, C.M., Marie, A.D., Humphries, R.E., Robertson, D.H., Cavaggioni, A., and Beynon, R.J. 2001. Individual recognition in mice mediated by major urinary proteins. Nature 414: $631-634$.

Hurst, L.D. 2002. The Ka/Ks ratio: Diagnosing the form of sequence evolution. Trends Genet. 18: 486.

Ishii, T., Hirota, J., and Mombaerts, P. 2003. Combinatorial coexpression of neural and immune multigene families in mouse vomeronasal sensory neurons. Curr. Biol. 13: 394-400.

Jansa, S.A., Lundrigan, B.L., and Tucker, P.K. 2003. Tests for positive selection on immune and reproductive genes in closely related species of the murine genus mus. J. Mol. Evol. 56: 294-307.

Kabsch, W. and Sander, C. 1983. Dictionary of protein secondary structure: Pattern recognition of hydrogen-bonded and geometrical features. Biopolymers 22: 2577-2637.

Kent, W.J. 2002. BLAT-The BLAST-like alignment tool. Genome Res. 12: $656-664$.

Kieffer, B., Driscoll, P.C., Campbell, I.D., Willis, A.C., van der Merwe, P.A., and Davis, S.J. 1994. Three-dimensional solution structure of the extracellular region of the complement regulatory protein CD59, a new cell-surface protein domain related to snake venom neurotoxins. Biochemistry 33: 4471-4482.

Knopf, J.L., Gallagher, J.F., and Held, W.A. 1983. Differential, multihormonal regulation of the mouse major urinary protein gene family in the liver. Mol. Cell Biol. 3: 2232-2240.

Krieger, J., Schmitt, A., Lobel, D., Gudermann, T., Schultz, G., Breer, H.,

\section{Genome Research}


and Boekhoff, I. 1999. Selective activation of G protein subtypes in the vomeronasal organ upon stimulation with urine-derived compounds. J. Biol. Chem. 274: 4655-4662.

Kunishima, N., Shimada, Y., Tsuji, Y., Sato, T., Yamamoto, M. Kumasaka, T., Nakanishi, S., Jingami, H., and Morikawa, K. 2000. Structural basis of glutamate recognition by a dimeric metabotropic glutamate receptor. Nature 407: 971-977.

Lane, R.P., Cutforth, T., Young, J., Athanasiou, M., Friedman, C., Rowen, L., Evans, G., Axel, R., Hood, L., and Trask, B.J. 2001. Genomic analysis of orthologous mouse and human olfactory receptor loci. Proc. Natl. Acad. Sci. 98: 7390-7395.

Lee, S. and van der Boot, L.M. 1955. Spontaneous pseudopregnancy in mice. Acta Physiol. Pharmacol. Neerl. 4: 442-443.

Lichtarge, O., Bourne, H.R., and Cohen, F.E. 1996. An evolutionary trace method defines binding surfaces common to protein families. J. Mol. Biol. 25 7: 342-358.

Lobel, D., Marchese, S., Krieger, J., Pelosi, P., and Breer, H. 1998. Subtypes of odorant-binding proteins-Heterologous expression and ligand binding. Eur. J. Biochem. 254: 318-324.

Loconto, J., Papes, F., Chang, E., Stowers, L., Jones, E.P., Takada, T., Kumanovics, A., Fischer Lindahl, K., and Dulac, C. 2003. Functional expression of murine $\mathrm{V} 2 \mathrm{R}$ pheromone receptors involves selective association with the M10 and M1 families of MHC class Ib molecules. Cell 112: 607-618.

Ma, W., Miao, Z., and Novotny, M.V. 1998. Role of the adrenal gland and adrenal-mediated chemosignals in suppression of estrus in the house mouse: The lee-boot effect revisited. Biol. Reprod. 59: 1317-1320.

Madabushi, S., Yao, H., Marsh, M., Kristensen, D.M., Philippi, A., Sowa, M.E., and Lichtarge, O. 2002. Structural clusters of evolutionary trace residues are statistically significant and common in proteins. J. Mol. Biol. 316: 139-154.

Matsunami, H. and Buck, L.B. 1997. A multigene family encoding a diverse array of putative pheromone receptors in mammals. Cell 90: $775-784$.

Menashe, I., Man, O., Lancet, D., and Gilad, Y. 2003. Different noses for different people. Nat. Genet. 34: 143-144.

Mirny, L.A. and Shakhnovich, E.I. 1999. Universally conserved positions in protein folds: Reading evolutionary signals about stability, folding kinetics and function. J. Mol. Biol. 291: 177-196.

Miyata, T. and Yasunaga, T. 1980. Molecular evolution of mRNA: A method for estimating evolutionary rates of synonymous and amino acid substitutions from homologous nucleotide sequences and its application. J. Mol. Evol. 16: 23-36.

Miyawaki, A., Matsushita, F., Ryo, Y., and Mikoshiba, K. 1994. Possible pheromone-carrier function of two lipocalin proteins in the vomeronasal organ. EMBO J. 13: 5835-5842.

Mucignat-Caretta, C., Caretta, A., and Cavaggioni, A. 1995. Acceleration of puberty onset in female mice by male urinary proteins. J. Physiol. 486 (Pt 2): 517-522.

Mundy, N.I. and Cook, S. 2003. Positive selection during the diversification of Class I vomeronasal receptor-like (V1RL) genes, putative pheromone receptor genes, in human and primate evolution. Mol. Biol. Evol. 20: 1805-1810.

Nielsen, R. and Yang, Z. 1998. Likelihood models for detecting positively selected amino acid sites and applications to the HIV-1 envelope gene. Genetics 148: 929-936.

Novotny, M.V., Ma, W., Wiesler, D., and Zidek, L. 1999. Positive identification of the puberty-accelerating pheromone of the house mouse: The volatile ligands associating with the major urinary protein. Proc. R Soc. Lond. B Biol. Sci. 266: 2017-2022.

Okada, T., Fujiyoshi, Y., Silow, M., Navarro, J., Landau, E.M., and Shichida, Y. 2002. Functional role of internal water molecules in rhodopsin revealed by X-ray crystallography. Proc. Natl. Acad. Sci. 99: 5982-5987.

Oliveira, L., Paiva, A.C., and Vriend, G. 2002. Correlated mutation analyses on very large sequence families. Chembiochem. 3: $1010-1017$.

Parmentier, M., Libert, F., Schurmans, S., Schiffmann, S., Lefort, A., Eggerickx, D., Ledent, C., Mollereau, C., Gerard, C., Perret, J., et al. 1992. Expression of members of the putative olfactory receptor gene family in mammalian germ cells. Nature 355: 453-455.

Peek, A.S., Souza, V., Eguiarte, L.E., and Gaut, B.S. 2001. The interaction of protein structure, selection, and recombination on the evolution of the type-1 fimbrial major subunit (fimA) from Escherichia coli. J. Mol. Evol. 52: 193-204.

Potts, W.K., Manning, C.J., and Wakeland, E.K. 1991. Mating patterns in seminatural populations of mice influenced by MHC genotype. Nature 352: 619-621.

Rat Genome Sequencing Project Consortium. 2004. Genome sequence of the Brown Norway Rat yields insights into mammalian evolution. Nature (in press).
Robertson, D.H., Cox, K.A., Gaskell, S.J., Evershed, R.P., and Beynon, R.J 1996. Molecular heterogeneity in the major urinary proteins of the house mouse Mus musculus. Biochem. J. 316 (Pt 1): 265-272.

Rost, B. and Sander, C. 1994. Conservation and prediction of solvent accessibility in protein families. Proteins 20: 216-226.

Rouquier, S., Taviaux, S., Trask, B.J., Brand-Arpon, V., van den Engh, G., Demaille, J., and Giorgi, D. 1998. Distribution of olfactory receptor genes in the human genome. Nat. Genet. 18: 243-250.

Ryba, N.J. and Tirindelli, R. 1997. A new multigene family of putative pheromone receptors. Neuron 19: 371-379.

Sander, C. and Schneider, R. 1993. The HSSP data base of protein structure-sequence alignments. Nucleic Acids Res. 21: 3105-3109.

Schaefer, M.L., Young, D.A., and Restrepo, D. 2001. Olfactory fingerprints for major histocompatibility complex-determined body odors. J. Neurosci. 21: 2481-2487.

Schaner, P., Richards, N., Wadhwa, A., Aksentijevich, I., Kastner, D., Tucker, P., and Gumucio, D. 2001. Episodic evolution of pyrin in primates: Human mutations recapitulate ancestral amino acid states. Nat. Genet. 27: 318-321.

Singer, A.G., Macrides, F., Clancy, A.N., and Agosta, W.C. 1986. Purification and analysis of a proteinaceous aphrodisiac pheromone from hamster vaginal discharge. J. Biol. Chem. 261: 13323-13326.

Singer, M.S. 2000. Analysis of the molecular basis for octanal interactions in the expressed rat 17 olfactory receptor. Chem. Senses 25: $155-165$.

Singh, P.B., Brown, R.E., and Roser, B. 1987. MHC antigens in urine as olfactory recognition cues. Nature 327: 161-164.

Southan, C., Cutler, P., Birrell, H., Connell, J., Fantom, K.G., Sims, M., Shaikh, N., and Schneider, K. 2002. The characterisation of novel secreted Ly- 6 proteins from rat urine by the combined use of two-dimensional gel electrophoresis, microbore high performance liquid chromatography and expressed sequence tag data. Proteomics 2: 187-196.

Speca, D.J., Lin, D.M., Sorensen, P.W., Isacoff, E.Y., Ngai, J., and Dittman, A.H. 1999. Functional identification of a goldfish odorant receptor. Neuron 23: 487-498.

Spehr, M., Gisselmann, G., Poplawski, A., Riffell, J.A., Wetzel, C.H., Zimmer, R.K., and Hatt, H. 2003. Identification of a testicular odorant receptor mediating human sperm chemotaxis. Science 299: 2054-2058.

Steinbrecht, R.A. 1998. Odorant-binding proteins: Expression and function. Ann. NY Acad. Sci. 855: 323-332.

Stockley, P. and Parker, G.A. 2002. Life history consequences of mammal sibling rivalry. Proc. Natl. Acad. Sci. 99: 12932-12937.

Swanson, W.J., Yang, Z., Wolfner, M.F., and Aquadro, C.F. 2001. Positive Darwinian selection drives the evolution of several female reproductive proteins in mammals. Proc. Natl. Acad. Sci. 98: 2509-2514.

Thompson, J.D., Higgins, D.G., and Gibson, T.J. 1994. CLUSTAL W: Improving the sensitivity of progressive multiple sequence alignment through sequence weighting, position-specific gap penalties and weight matrix choice. Nucleic Acids Res. 22: $4673-4680$.

Timm, D.E., Baker, L.J., Mueller, H., Zidek, L., and Novotny, M.V. 2001. Structural basis of pheromone binding to mouse major urinary protein (MUP-I). Protein Sci. 10: 997-1004.

Tsuchiya, D., Kunishima, N., Kamiya, N., Jingami, H., and Morikawa, K. 2002. Structural views of the ligand-binding cores of a metabotropic glutamate receptor complexed with an antagonist and both glutamate and Gd3+. Proc. Natl. Acad. Sci. 99: 2660-2665.

Vaidehi, N., Floriano, W.B., Trabanino, R., Hall, S.E., Freddolino, P., Choi, E.J., Zamanakos, G., and Goddard III, W.A. 2002. Prediction of structure and function of G protein-coupled receptors. Proc. Natl. Acad. Sci. 99: 12622-12627.

Vandenbergh, J.G. 1976. Acceleration of sexual maturation in female rats by male stimulation. J. Reprod. Fertil. 46: 451-453.

Vandenbergh, J.G. 1989. Coordination of social signals and ovarian function during sexual development. J. Anim. Sci. 67: 1841-1847.

Vanderhaeghen, P., Schurmans, S., Vassart, G., and Parmentier, M. 1997. Specific repertoire of olfactory receptor genes in the male germ cells of several mammalian species. Genomics 39: 239-246.

Waterston, R.H., Lindblad-Toh, K., Birney, E., Rogers, J., Abril, J.F., Agarwal, P., Agarwala, R., Ainscough, R., Alexandersson, M., An, P., et al. 2002. Initial sequencing and comparative analysis of the mouse genome. Nature 420: 520-562.

Wes, P.D., Chevesich, J., Jeromin, A., Rosenberg, C., Stetten, G., and Montell, C. 1995. TRPC1, a human homolog of a Drosophila store-operated channel. Proc. Natl. Acad. Sci. 92: 9652-9656.

Wess, J. 1997. G-protein-coupled receptors: Molecular mechanisms involved in receptor activation and selectivity of G-protein recognition. FASEB J. 11: 346-354.

Whitten, W.K. 1958. Modification of the oestrus cycle of the mouse by 
Emes et al.

external stimuli associated with the male. Changes in the oestrus cycle determined by vaginal smears. J. Endochrinol. 17: 307-313.

Wood, T.C. and Pearson, W.R. 1999. Evolution of protein sequences and structures. J. Mol. Biol. 291: 977-995.

Yang, Z. 1997. PAML: A program package for phylogenetic analysis by maximum likelihood. Comput. Appl. Biosci. 13: 555-556.

Yang, Z. and Nielsen, R. 2000. Estimating synonymous and nonsynonymous substitution rates under realistic evolutionary models. Mol. Biol. Evol. 17: 32-43.

Yang, Z. and Nielsen, R. 2002. Codon-substitution models for detecting molecular adaptation at individual sites along specific lineages. $\mathrm{Mol}$. Biol. Evol. 19: 908-917.

Yang, Z. and Swanson, W.J. 2002. Codon-substitution models to detect adaptive evolution that account for heterogeneous selective pressures among site classes. Mol. Biol. Evol. 19: 49-57.

Yang, Z., Nielsen, R., and Hasegawa, M. 1998. Models of amino acid substitution and applications to mitochondrial protein evolution. Mol. Biol. Evol. 15: 1600-1611.

Yang, Z., Nielsen, R., Goldman, N., and Pedersen, A.M. 2000a. Codon-substitution models for heterogeneous selection pressure at amino acid sites. Genetics 155: 431-449.

Yang, Z., Swanson, W.J., and Vacquier, V.D. $2000 \mathrm{~b}$. Maximum-likelihood analysis of molecular adaptation in abalone sperm lysin reveals variable selective pressures among lineages and sites. Mol. Biol. Evol. 17: 1446-1455.

Young, J.M. and Trask, B.J. 2002. The sense of smell: Genomics of vertebrate odorant receptors. Hum. Mol. Genet. 11: 1153-1160.
Young, J.M., Friedman, C., Williams, E.M., Ross, J.A., Tonnes-Priddy, L., and Trask, B.J. 2002. Different evolutionary processes shaped the mouse and human olfactory receptor gene families. Hum. Mol. Genet. 11: $535-546$.

Zanotto, P.M., Kallas, E.G., de Souza, R.F., and Holmes, E.C. 1999. Genealogical evidence for positive selection in the nef gene of HIV-1. Genetics 153: 1077-1089.

Zhang, X. and Firestein, S. 2002. The olfactory receptor gene superfamily of the mouse. Nat. Neurosci. 5: 124-133.

Zhao, X.J., Zhao, J., Zhou, Q., and Sims, P.J. 1998. Identity of the residues responsible for the species-restricted complement inhibitory function of human CD59. J. Biol. Chem. 273: 10665-10671.

\section{WEB SITE REFERENCES}

abacus.gene.ucl.ac.uk/software/paml.html; PAML home page. www.ensembl.org/; Ensembl Genome browser. genome.cse.ucsc.edu/; UCSC Genome browser.

senselab.med.yale.edu/senselab/ORDB/; Olfactory receptor Database (ORDB).

www.rcsb.org/pdb/; The Protein Data Bank.

www.povray.org/; Povray Ray tracing Web site.

www.expasy.org/spdbv/; Swiss Pdb-Viewer.

Received September 5, 2003; accepted in revised form November 17, 2003. 


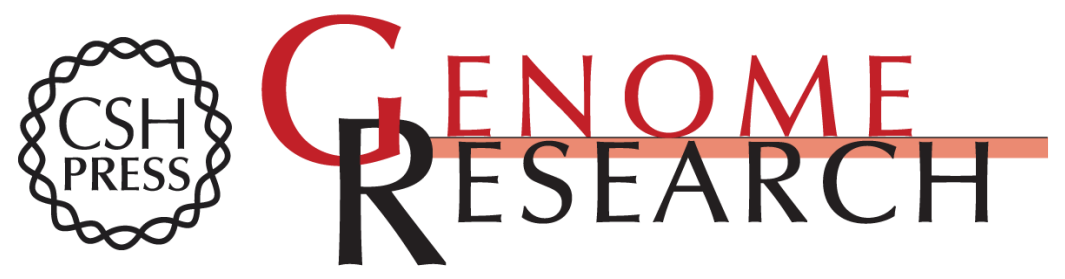

\section{Evolution and Comparative Genomics of Odorant- and Pheromone-Associated Genes in Rodents}

Richard D. Emes, Scott A. Beatson, Chris P. Ponting, et al.

Genome Res. 2004 14: 591-602

Access the most recent version at doi:10.1101/gr.1940604

Supplemental Material

References

License

Email Alerting Service
http://genome.cshlp.org/content/suppl/2004/04/02/14.4.591.DC1

This article cites 108 articles, 25 of which can be accessed free at: http://genome.cshlp.org/content/14/4/591.full.html\#ref-list-1

Receive free email alerts when new articles cite this article - sign up in the box at the top right corner of the article or click here.

\section{Affordable, Accurate Sequencing.}

To subscribe to Genome Research go to: https://genome.cshlp.org/subscriptions 